\title{
Performance Verification of Impact Machines for Testing Plastics
}

T. A. Siewert, D. P. Vigliotti, L. B. Dirling, and C. N. McCowan

National Institute of Standards and Technology, Boulder, Colorado 80303
Valid comparison of impact test energies reported by various organizations and over time depends on consistent performance of impact test machines. This paper investigates the influence of various specimen and test parameters on impact energies in the $1 \mathrm{~J}$ to $2 \mathrm{~J}$ range for both Charpy V-notch and Izod procedures, leading toward the identification of a suitable material for use in a program to verify machine performance. We investigated the influences on the absorbed energy of machine design, test material, specimen cross sectional area, and machine energy range. For comparison to published round robin data on common plastics, this study used some common metallic alloys, including those used in the international verification program for metals impact machines and in informal calibration pro- grams of tensile machines. The alloys that were evaluated include AISI type 4340 steel, and five aluminum alloys: 2014-T6, 2024-T351, 2219-T87, 6061-T6, and 7075-T6. We found that certain metallic alloys have coefficients of variation comparable to those of the best plastics that are reported in the literature. Also, we found that the differences in absorbed energy between two designs of machines are smaller than the differences that can be attributed to the specimens alone.

Key words: aluminum; Charpy impact test; Izod impact test; plastics; steel; verification; V-notch.

Accepted: October 13, 1999

Available online: http://www.nist.gov/jres

\section{Introduction}

About 40 years ago, a requirement for the use of verification specimens was added to the standard for impact testing of metals, American Society for Testing and Materials (ASTM) Standard E 23 [1]. This occurred because the metals impact testing community discovered that verification tests of impact machine performance using reference specimens were able to detect certain energy loss mechanisms, mechanisms that could not otherwise be observed during traditional physicsbased measurements of machine performance (pendulum period, mass, mechanical friction, windage, etc.). This present paper evaluates the use of verification specimens for machines used to test plastics, and suggests what information these specimens provide about machine performance.

Few studies on performance issues for plastics impact machines could be found. For our purposes, one of the most useful was the one used to support the precision statement in ASTM Standard D 256, "Standard Test Methods for Impact Resistance of Plastics and Electrical Insulating Materials" [2]. That report describes a round robin that included six different plastics and 25 different laboratories. It indicates that both the materials and the laboratories make significant contributions to the uncertainty in the data. Another study, also an ASTM research report, indicates that the effect of notch radius (for plas- 
tic materials) is linear over the range of notch radii of $0.03 \mathrm{~mm}$ to $2.5 \mathrm{~mm} \mathrm{[3]}$.

\section{Procedure}

\subsection{Material Selection}

The first material to be included in the test plan was AISI type 4340 steel (of a special, high-purity grade) since this has been used for many years to make verification specimens for metals impact machines. Therefore, it serves as a good benchmark against which other materials can be measured. We compared this 4340 steel to several aluminum alloys: 2014-T6, 2024-T351, 2219T87, 6061-T6, and 7075-T6. Alloy 6061-T6 was selected because of its reproducible performance in some informal tensile testing programs. The other aluminum alloys were selected because they are readily available, and also because they are known to possess a good blend of strength and ductility in structural applications. All these aluminum alloys have a lower modulus (stiffness), about $70 \mathrm{GPa}$, than the 4340 steel, about $200 \mathrm{GPa}$ [4]. This means that they deform at a force lower than for steels, yet still at a force much greater than for plastics, whose moduli usually fall between $2 \mathrm{GPa}$ and $12 \mathrm{GPa}$ [5]. A higher modulus in the verification test material is not necessarily detrimental, since it can serve to better identify an energy loss mechanism in an impact machine that is due to internal friction in the components that are loaded during fracture. The larger oscillation during these higher loads with metal specimens helps us to determine whether this effect is significant during routine testing with plastic specimens.

Stability of impact energy over time is one of the most desirable features in the verification specimens used to assess machine performance. The 4340 steel has a shelf life of at least several years, and so is a good benchmark against which other materials can be measured. Although aluminum alloys such as the 2000, 6000, and 7000 series age harden, these effects were minimized through careful selection of alloy and lots. The 6061 and 7075 alloys were treated at elevated temperature (although lower than the tempering treatments for the 4340 steel), and the steep reduction in diffusion rate with temperature drastically limits subsequent aging at room temperature. The 2000 series alloys will age at room temperature, but $80 \%$ to $90 \%$ of the hardening is completed in 4 to 5 days [6]. To minimize the small amount of residual aging, we took our specimens from bars and plates that had been in inventory for several years. In summary, we expect very little change over time in the mechanical properties of specimens made from these metallic materials.

Another desirable feature for verification specimens is complete fracture of the specimens during impact. Complete fracture is preferred because we can compare the marks on both fractured halves. The specimens develop marks during the initial strike (when the pendulum hits the specimen), during fracture, and during subsequent collisions as the specimens leave the machines. Assessment of these marks during the post-test evaluation of the specimens (part of the metals impact test ASTM Standard E 23 procedures) provides guidance to machine owners about alignment problems and wear.

We did not include any plastics in this evaluation, because sufficient reference data exist in the two reports cited in the introduction. The goal of this study was to compare the data for these candidate metals to the existing data for the plastics.

\subsection{Specimen Design and Preparation}

We selected a specimen configuration (Fig. 1) that was designed to supplement the machine verification tests described in International Organization for Standardization (ISO) Draft International Standard (DIS) 13802 [7]. The dimensions were selected based on the plastic specimens described in ASTM Standard D256, but were changed where necessary to allow for the different materials properties of the metals. We permitted deviations from the standard configuration, such as side grooves on each side of the notch in some specimens, and allowing the length to be that specified either for Charpy or for Izod impact testing. One of the goals of this study was to determine the energies that would be developed by specimens of various sizes. The approach taken in the metals impact standard is to verify the machine performance, using specimens distributed over the useful range of the machine (up to $80 \%$ of the machine capacity). For a $22 \mathrm{~J}$ impact machine, this means specimens with energies from $1 \mathrm{~J}$ or $2 \mathrm{~J}$, up to about $15 \mathrm{~J}$.

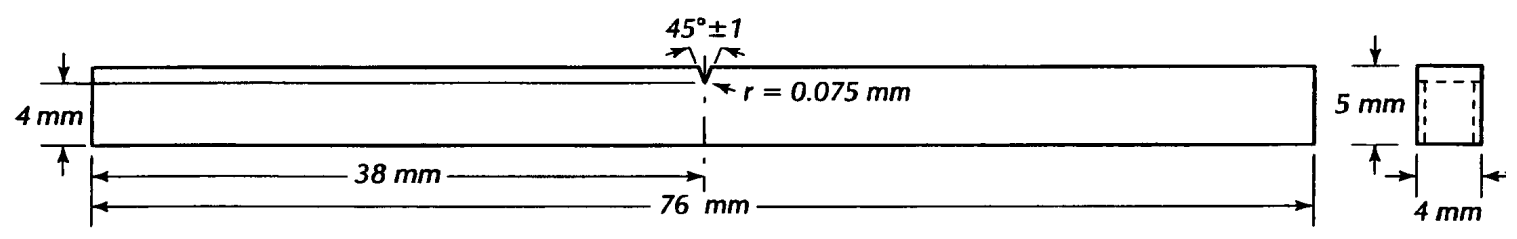

Fig. 1. Charpy specimen design. When side grooves were used, each side was grooved to a depth of $0.25 \mathrm{~mm}$ with a $45^{\circ}$ cutter. 
The standard configuration for the type 4340 steel specimens used in metal impact machines (as described in ASTM Standard E 23) has a cross section of $10 \mathrm{~mm}$ by $10 \mathrm{~mm}$ [1]. When heat-treated to produce a low energy, this specimen configuration absorbs about $15 \mathrm{~J}$ of energy from the pendulum. This $15 \mathrm{~J}$ specimen seemed appropriate to evaluate the performance of our plastics impact machine when configured for its maximum capacity of $22 \mathrm{~J}$. However, our machine was damaged in an attempt to break one of these specimens in some preliminary tests. Apparently, our machine is able to tolerate energies in this range only when the fracture event is spread over a longer time, such as when the low modulus plastic specimens deform before fracture. The impact energy is a single number that is the integral of the incremental resistance of the specimen to fracture as the pendulum swings through its range. Therefore, by itself, the impact energy reading is an inaccurate way to compare the responses of low- and high-modulus materials, since it does not reflect the influence of the maximum load on the machine-specimen interactions.

After the impact machine was repaired, we continued our initial evaluations (to establish the experiment design) using miniature specimens designed to evaluate only the lower end of the machine range, between $1 \mathrm{~J}$ and $2 \mathrm{~J}$. We selected steel specimen cross sections of 5 $\mathrm{mm}$ by $5 \mathrm{~mm}, 4 \mathrm{~mm}$ by $5 \mathrm{~mm}$ (notched across the $4 \mathrm{~mm}$ face), and $4 \mathrm{~mm}$ by $4 \mathrm{~mm}$ for some preliminary tests. This size range was designed to determine the cross section that would produce energies within the desired range, as well as a specimen size that would completely fracture upon impact. Another reason for concentrating on specimens of lower energy in the rest of this paper is that metal specimens show more ductility in thinner sections. Future tests with larger specimens, for the higher end of the machine capacity, should exhibit a more brittle fracture.

The impact data from the four specimens tested with each of the three cross sections, $4 \mathrm{~mm}$ by $4 \mathrm{~mm}, 4 \mathrm{~mm}$ by $5 \mathrm{~mm}$, and $5 \mathrm{~mm}$ by $5 \mathrm{~mm}$, were compared to the cross-sectional area. To obtain the cross-sectional area, we multiplied the two dimensions and subtracted the area of the notched region (1 $\mathrm{mm}$ deep) from the product. We found a linear relationship between crosssectional area and energy (at least for this limited energy range), then used these data to standardize on a specimen dimension of $4 \mathrm{~mm}$ by $5 \mathrm{~mm}$ for the majority of our tests, since this size fell near the center of the desired energy range.

Unfortunately, the specimens in these preliminary tests did not completely separate into halves upon impact. Even the $5 \mathrm{~mm}$ by $5 \mathrm{~mm}$ specimens left the machine with the two halves still joined by a thin ligament, but bent at about a $90^{\circ}$ angle by the impact. The ligament was so thin that the specimen halves could be bent to a $180^{\circ}$ angle with two fingers, at which point the two halves would separate. Therefore, the specimen absorbed almost all the energy needed to fracture it (and also absorbed the kinetic (toss) energy imparted by the striker), but we did not gain data on possible jamming between the striker and anvils that might occur as broken halves left the machine. While the standard $10 \mathrm{~mm}$ by $10 \mathrm{~mm}$ specimen in a metals impact test shows almost no ductility and leaves the machine in two halves traveling at high velocity, all specimens in the range of $4 \mathrm{~mm}$ by $4 \mathrm{~mm}$ to $5 \mathrm{~mm}$ by $5 \mathrm{~mm}$ showed substantial ductility. Therefore, an optimal cross section is nearer to $10 \mathrm{~mm}$ by $10 \mathrm{~mm}$, but we decided not to increase the section size since it would increase the energy beyond the desired range.

A thorough evaluation of all variables calls for a full factorial experimental program with a large number of replicate tests, which was beyond the scope, budget, and time available for this paper. Rather, this paper is an initial evaluation to determine which variables might be most important and should provide the basis for selection of the variables to include in a future round robin. Nevertheless, we have used statistical summaries of the data using common formulas to give some estimates of repeatability.

\subsection{Machine Design}

Our plastics impact machine can evaluate both Charpy V-notch and Izod specimens, which allowed us to develop data in the two different test configurations. The number of specimens tested using the Izod technique was much smaller than that tested using the Charpy technique, and was sufficient only to estimate if there were some differences in the coefficients of variation for these specimens between the two configurations. Although many companies follow the Charpy Vnotch and Izod impact test procedures described in ASTM Standard D 256, we have seen a growing interest in ISO Standard DIS 13802, and decided to follow its procedural requirements. Differences between these two standards include anvil spacing, included angle and radius of the striker tip, anvil radius, and many other details of the test procedure. These differences preclude direct comparison of the means between specimens tested according to the two standards, but we believe that the differences are sufficiently minor to conclude that the standard deviations and coefficients of variation (CVs, or relative standard deviations) should be about the same.

While most tests were performed using a single machine set up for a full-scale capacity of $22 \mathrm{~J}$, we also removed the masses bolted to the pendulum, reducing 
the machine range for several tests to $5 \mathrm{~J}$. We also performed some tests using a conventional metals impact machine with a capacity of $358 \mathrm{~J}$, and using another design of plastics impact machine configured for a capacity of $22 \mathrm{~J}$.

\section{Results and Discussion}

All of the data from our tests are included in Table 1 (Charpy) and Table 2 (Izod). This body of data consists of sets of similar specimens, typically sets of 3 to 10 specimens each, so we could evaluate the scatter between the specimens tested at the same set of conditions.
A summary of these data is listed in Table 3, which combines the data in each set.

Tables 1 and 2 contain columns that describe all of the parameters that were varied or measured in the evaluation. Even when summarized in Table 3, this large body of data makes comparisons difficult, so we have selected subsets of the data in the following discussion to highlight the effects of the different parameters. These subsets exclude the columns with data that were held constant (listed in the notes below each table), but add columns with the calculated standard deviations and coefficients of variation. For the 4340 steel, comparisons are made only between data from sets that were heat treated in the same batch (with similar prefixes).

Table 1. Verification of Charpy impact machine in testing plastics

\begin{tabular}{|c|c|c|c|c|c|c|}
\hline $\begin{array}{l}\text { Specimen } \\
\text { ID }\end{array}$ & Material & $\begin{array}{c}\text { Absorbed } \\
\text { energy } \\
\text { (J) }\end{array}$ & $\begin{array}{l}\text { Notch } \\
\text { radius } \\
(\mathrm{mm})\end{array}$ & $\begin{array}{l}\text { Specimen } \\
\text { dimensions } \\
(\mathrm{mm})\end{array}$ & $\begin{array}{l}\text { Potential } \\
\text { energy } \\
\text { (J) }\end{array}$ & Comments \\
\hline 20 & 6061-T6 & 3.576 & 0.50 & 4 by 5 & 5 & Remaining ligament \\
\hline 21 & 6061-T6 & 3.648 & 0.50 & 4 by 5 & 5 & Remaining ligament \\
\hline 22 & 6061-T6 & 3.338 & 0.50 & 4 by 5 & 5 & Complete breaks \\
\hline 23 & 6061-T6 & 3.301 & 0.50 & 4 by 5 & 22 & Remaining ligament \\
\hline 24 & 6061-T6 & 3.571 & 0.50 & 4 by 5 & 22 & Remaining ligament \\
\hline 25 & 6061-T6 & 3.550 & 0.50 & 4 by 5 & 22 & Complete breaks \\
\hline 26 & 6061-T6 & 3.036 & 0.25 & 4 by 5 & 22 & Complete breaks \\
\hline 27 & 6061-T6 & 3.435 & 0.25 & 4 by 5 & 22 & Complete breaks \\
\hline 28 & 6061-T6 & 2.858 & 0.25 & 4 by 5 & 22 & Complete breaks \\
\hline 29 & 7075-T6 & 1.138 & 0.25 & 4 by 5 & 22 & Complete laminate breaks \\
\hline 30 & 7075-T6 & 1.138 & 0.25 & 4 by 5 & 22 & Complete laminate breaks \\
\hline 31 & $7075-\mathrm{T} 6$ & 1.239 & 0.25 & 4 by 5 & 22 & Complete laminate breaks \\
\hline 32 & 2219-T87 & 1.245 & 0.25 & 4 by 5 & 22 & Complete brittle fracture \\
\hline 33 & 2219-T87 & 1.320 & 0.25 & 4 by 5 & 22 & Complete brittle fracture \\
\hline 34 & 2219-T87 & 1.382 & 0.25 & 4 by 5 & 22 & Complete brittle fracture \\
\hline 35 & 2014-T6 & 2.889 & 0.25 & 4 by 5 & 22 & Complete laminated fracture \\
\hline 36 & 2014-T6 & 3.000 & 0.25 & 4 by 5 & 22 & Complete laminated fracture \\
\hline 37 & 2014-T6 & 2.791 & 0.25 & 4 by 5 & 22 & Complete laminated fracture \\
\hline 38 & 2024-Т351 & 1.970 & 0.25 & 4 by 5 & 22 & Complete brittle fracture \\
\hline 39 & 2024-Т351 & 1.829 & 0.25 & 4 by 5 & 22 & Complete brittle fracture \\
\hline 40 & 2024-T351 & 1.807 & 0.25 & 4 by 5 & 22 & Complete brittle fracture \\
\hline 41 & 6061-T6 & 3.084 & 0.50 & 4 by 5 & 358 & Compare to $26,27,28$ \\
\hline 42 & 6061-T6 & 3.084 & 0.50 & 4 by 5 & 358 & Compare to $26,27,28$ \\
\hline 43 & 6061-T6 & 3.084 & 0.50 & 4 by 5 & 358 & Compare to $26,27,28$ \\
\hline 44 & 6061-T6 & 3.168 & 0.25 & 4 by 5 & 358 & Compare to A, B \\
\hline $\mathrm{C}$ & 7075 & 1.498 & 0.25 & 4 by 5 & 358 & \\
\hline $\mathrm{D}$ & 7075 & 1.581 & 0.25 & 4 by 5 & 358 & \\
\hline E & 7075 & 1.831 & 0.25 & 4 by 5 & 358 & \\
\hline $\mathrm{F}$ & 7075 & 1.664 & 0.25 & 4 by 5 & 358 & \\
\hline 45 & 4340 & 2.917 & 0.25 & 5 by 5 & 358 & \\
\hline 46 & 4340 & 3.168 & 0.25 & & 358 & \\
\hline 47 & 4340 & 3.001 & 0.25 & $5 \times 5$ & 358 & \\
\hline 48 & 4340 & 3.001 & 0.25 & $5 \times 5$ & 358 & \\
\hline 49 & 4340 & 1.581 & 0.25 & 4 by 4 & 358 & \\
\hline $56-72$ & 4340-LL56 & 4.552 & 0.25 & 4 by 5 & 22 & \\
\hline $56-73$ & 4340-LL56 & 4.357 & 0.25 & 4 by 5 & 22 & \\
\hline $56-74$ & 4340-LL56 & 4.414 & 0.25 & 4 by 5 & 22 & \\
\hline
\end{tabular}


Table 1. Verification of Charpy impact machine in testing plastics-Continued

\begin{tabular}{|c|c|c|c|c|c|c|}
\hline $\begin{array}{l}\text { Specimen } \\
\text { ID }\end{array}$ & Material & $\begin{array}{c}\text { Absorbed } \\
\text { energy } \\
(\mathbf{J})\end{array}$ & $\begin{array}{l}\text { Notch } \\
\text { radius } \\
(\mathrm{mm})\end{array}$ & $\begin{array}{l}\text { Specimen } \\
\text { dimensions } \\
(\mathrm{mm})\end{array}$ & $\begin{array}{l}\text { Potential } \\
\text { energy } \\
\text { (J) }\end{array}$ & Comments \\
\hline $56-1$ & 4340-LL56 & 4.386 & 0.25 & 4 by 5 & 22 & No side groove \\
\hline $56-2$ & 4340-LL56 & 4.484 & 0.25 & 4 by 5 & 22 & No side groove \\
\hline $56-3$ & 4340-LL56 & 4.573 & 0.25 & 4 by 5 & 22 & No side groove \\
\hline $56-4$ & 4340-LL56 & 4.430 & 0.25 & 4 by 5 & 22 & No side groove \\
\hline $56-5$ & 4340-LL56 & 4.568 & 0.25 & 4 by 5 & 22 & No side groove \\
\hline $56-6$ & 4340-LL56 & 4.470 & 0.25 & 4 by 5 & 22 & No side groove \\
\hline $56-7$ & 4340-LL56 & 4.382 & 0.25 & 4 by 5 & 22 & No side groove \\
\hline $56-8$ & 4340-LL56 & 4.457 & 0.25 & 4 by 5 & 22 & No side groove \\
\hline $56-9$ & 4340-LL56 & 4.546 & 0.25 & 4 by 5 & 22 & No side groove \\
\hline $56-10$ & 4340-LL56 & 4.298 & 0.25 & 4 by 5 & 22 & No side groove \\
\hline $56-31 S$ & 4340-LL56 & 2.363 & 0.25 & 4 by 5 & 22 & Side groove \\
\hline $56-32 S$ & 4340-LL56 & 2.467 & 0.25 & 4 by 5 & 22 & Side groove \\
\hline $56-33 \mathrm{~S}$ & 4340-LL56 & 2.495 & 0.25 & 4 by 5 & 22 & Side groove \\
\hline $56-34 S$ & 4340-LL56 & 2.519 & 0.25 & 4 by 5 & 22 & Side groove \\
\hline $56-35 \mathrm{~S}$ & 4340-LL56 & 2.535 & 0.25 & 4 by 5 & 22 & Side groove \\
\hline $56-36 \mathrm{~S}$ & 4340-LL56 & 2.483 & 0.25 & 4 by 5 & 22 & Side groove \\
\hline $56-37 \mathrm{~S}$ & 4340-LL56 & 2.447 & 0.25 & 4 by 5 & 22 & Side groove \\
\hline $56-38 S$ & 4340-LL56 & 2.535 & 0.25 & 4 by 5 & 22 & Side groove \\
\hline $56-39 S$ & 4340-LL56 & 2.447 & 0.25 & 4 by 5 & 22 & Side groove \\
\hline $56-40 \mathrm{~S}$ & 4340-LL56 & 2.404 & 0.25 & 4 by 5 & 22 & Side groove \\
\hline LL11-1 & 4340 & 2.888 & 0.25 & 4 by 5 & 22 & Machine \#2, no side groove \\
\hline LL11-2 & 4340 & 2.739 & 0.25 & 4 by 5 & 22 & Machine \#2, no side groove \\
\hline LL11-3 & 4340 & 2.725 & 0.25 & 4 by 5 & 22 & Machine \#2, no side groove \\
\hline LL11-4 & 4340 & 2.793 & 0.25 & 4 by 5 & 22 & Machine \#2, no side groove \\
\hline LL11-5 & 4340 & 2.725 & 0.25 & 4 by 5 & 22 & Machine \#2, no side groove \\
\hline LL11-6 & 4340 & 2.685 & 0.25 & 4 by 5 & 22 & Machine \#2, no side groove \\
\hline LL11-7 & 4340 & 2.698 & 0.25 & 4 by 5 & 22 & Machine $\# 2$, no side groove \\
\hline LL11-8 & 4340 & 2.671 & 0.25 & 4 by 5 & 22 & Machine \#2, no side groove \\
\hline LL11-9 & 4340 & 2.671 & 0.25 & 4 by 5 & 22 & Machine \#2, no side groove \\
\hline LL11-10 & 4340 & 2.752 & 0.25 & 4 by 5 & 22 & Machine \#2, no side groove \\
\hline LA46-1 & 4340 & 2.210 & 0.25 & 4 by 5 & 22 & Machine \#2, side groove \\
\hline LA46-2 & 4340 & 2.115 & 0.25 & 4 by 5 & 22 & Machine \#2, side groove \\
\hline LA46-3 & 4340 & 1.424 & 0.25 & 4 by 5 & 22 & Machine \#2, side groove \\
\hline LA46-4 & 4340 & 1.356 & 0.25 & 4 by 5 & 22 & Machine \#2, side groove \\
\hline LA46-5 & 4340 & 1.315 & 0.25 & 4 by 5 & 22 & Machine \#2, side groove \\
\hline LA46-6 & 4340 & 1.302 & 0.25 & 4 by 5 & 22 & Machine \#2, side groove \\
\hline LA46-7 & 4340 & 1.342 & 0.25 & 4 by 5 & 22 & Machine \#2, side groove \\
\hline LA46-8 & 4340 & 1.410 & 0.25 & 4 by 5 & 22 & Machine \#2, side groove \\
\hline LA46-9 & 4340 & 1.356 & 0.25 & 4 by 5 & 22 & Machine \#2, side groove \\
\hline LA46-10 & 4340 & 1.397 & 0.25 & 4 by 5 & 22 & Machine \#2, side groove \\
\hline G7 & 2219-T87 & 0.759 & 0.25 & 4 by 5 & 22 & Machine \#2, no side groove \\
\hline G8 & 2219-T87 & 0.705 & 0.25 & 4 by 5 & 22 & Machine $\# 2$, no side groove \\
\hline G9 & $2024 \mathrm{~T}-351$ & 1.071 & 0.25 & 4 by 5 & 22 & Machine \#2, no side groove \\
\hline G10 & $2024 \mathrm{~T}-351$ & 1.071 & 0.25 & 4 by 5 & 22 & Machine \#2, no side groove \\
\hline G13 & 2014-T6 & 2.386 & 0.25 & 4 by 5 & 22 & Machine \#2, no side groove \\
\hline G14 & 2014-T6 & 1.302 & 0.25 & 4 by 5 & 22 & Machine \#2, no side groove \\
\hline G3 & 7075-T6 & 1.152 & 0.25 & 4 by 5 & 22 & Machine \#2, no side groove \\
\hline G4 & 7075-T6 & 0.936 & 0.25 & 4 by 5 & 22 & Machine \#2, no side groove \\
\hline G1 & 6061-T6 & 2.088 & 0.50 & 4 by 5 & 22 & Machine \#2, no side groove \\
\hline G2 & 6061-T6 & 1.966 & 0.50 & 4 by 5 & 22 & Machine $\# 2$, no side groove \\
\hline G5 & 6061-T6 & 1.790 & 0.50 & 4 by 5 & 22 & Machine \#2, no side groove \\
\hline G6 & 6061-T6 & 2.766 & 0.50 & 4 by 5 & 22 & Machine \#2, no side groove \\
\hline G11 & 7075-T6 & 0.664 & 0.25 & 4 by 5 & 22 & Machine $\# 2$, no side groove \\
\hline G12 & 7075-T6 & 0.610 & 0.25 & 4 by 5 & 22 & Machine \#2, no side groove \\
\hline
\end{tabular}


Table 2. Verification of lzod impact machine in testing plastics

\begin{tabular}{cllllll}
\hline \hline $\begin{array}{c}\text { Specimen } \\
\text { ID }\end{array}$ & Material & $\begin{array}{c}\text { Absorbed } \\
\text { energy } \\
(\mathrm{J})\end{array}$ & $\begin{array}{c}\text { Notch } \\
\text { radius } \\
(\mathrm{mm})\end{array}$ & $\begin{array}{c}\text { Specimen } \\
\text { dimensions } \\
(\mathrm{mm})\end{array}$ & $\begin{array}{c}\text { Potential } \\
\text { energy } \\
(\mathrm{J})\end{array}$ & Comments \\
\hline 1 & 4340 & 1.311 & 0.25 & 4 by 4 & 22 & Remaining ligament \\
2 & 4340 & 1.777 & 0.25 & 4 by 4 & 22 & Remaining ligament \\
3 & $6061-\mathrm{T} 6$ & 2.743 & 0.25 & 4 by 5 & 22 & Remaining ligament \\
4 & $6061-\mathrm{T} 6$ & 2.891 & 0.25 & 4 by 5 & 22 & Remaining ligament \\
5 & $6061-\mathrm{T} 6$ & 2.580 & 0.25 & 4 by 5 & 22 & Remaining ligament \\
6 & $6061-\mathrm{T} 6$ & 2.817 & 0.25 & 4 by 5 & 22 & Remaining ligament \\
7 & $6061-\mathrm{T} 6$ & 2.461 & 0.25 & 4 by 5 & 22 & Remaining ligament \\
A & $7075-\mathrm{T} 6$ & 1.756 & 0.25 & 4 by 5 & 22 & Remaining ligament \\
B & $7075-\mathrm{T} 6$ & 1.390 & 0.25 & 4 by 5 & 22 & Remaining ligament \\
8 & 4340 & 1.331 & 0.25 & 4 by 4 & 22 & Remaining ligament \\
9 & 4340 & 1.314 & 0.25 & 4 by 4 & 22 & Remaining ligament \\
10 & 4340 & 1.314 & 0.25 & 4 by 4 & 22 & Remaining ligament \\
11 & 4340 & 2.043 & 0.25 & 4 by 5 & 22 & Remaining ligament \\
12 & 4340 & 2.150 & 0.25 & 4 by 5 & 22 & Remaining ligament \\
14 & 4340 & 2.125 & 0.25 & 4 by 5 & 22 & Remaining ligament \\
15 & 4340 & 2.484 & 0.25 & 5 by 5 & 22 & Remaining ligament \\
16 & 4340 & 2.449 & 0.25 & 5 by 5 & 22 & Remaining ligament \\
17 & 4340 & 2.557 & 0.25 & 5 by 5 & 22 & Remaining ligament \\
18 & 4340 & 2.537 & 0.25 & 5 by 5 & 22 & Remaining ligament \\
19 & 4340 & 2.731 & 0.25 & 5 by 5 & 22 & Remaining ligament \\
& & & & & & \\
\hline
\end{tabular}

\subsection{Test Material}

Table 4 includes summary data for the six materials (one steel and five aluminum alloys) included in this investigation, and is intended primarily to compare the repeatability of the different materials. The statistical data should be used with care in comparing the different materials, since the values are based on only three specimens for each material. Also, standard deviations cannot be compared fairly when the means are different. Therefore, the next column lists the coefficients of variation (CVs), which are the standard deviations divided by the means, and which are also commonly called relative standard deviations. These permit easier comparison of repeatability among specimen types and shapes with different means, but they do also suffer from the same statistical deficiency that comes from having only three specimens. We can thus make only broad generalizations about the data.

The data for the metals seem to fit into three groups according to the coefficient of variation: $\mathrm{CV}$ up to 0.036 , CV near 0.05 , and CV near 0.1 . We compared these to the interlaboratory data reported for plastics in Table 1 of ASTM Standard D256-93a [2]. These data fell into two groups: coefficients of variation between 0.042 and 0.058 for the plastics with lower energy absorption (phenolic, acetal, reinforced nylon, and polypropylene), and coefficients of variation between 0.012 and 0.018 for the plastics with higher energy absorption (ABS and polycarbonate). The summary of these data in ASTM Standard D256 does not mention the material thickness; instead, it uses the usual plastics convention of normalizing the energy to $25 \mathrm{~mm}$ of specimen width (notch length). This facilitates comparison of plastics of different sheet thicknesses (often $3 \mathrm{~mm}$ to $12.7 \mathrm{~mm}$ ), but makes analysis of the data in terms of machine energy range more difficult. Nevertheless, for a given machine range, the plastics with lower energy absorption will obviously yield data that are at the lower end of that machine range.

The ductile plastics have low CVs and so should be suitable for assessing machine repeatability at the high end of the machine range. At the low end of the machine range, the metals with the lower CVs (especially 4340 steel) beat the best of the plastics, by about a factor of two. Therefore, at the low end of the machine capacity, metals offer the possibility of at least matching the ability of specimens of plastics in resolving machine repeatability or the source of machine uncertainties. In addition, metals specimens put a larger load on the machine striker and frame, better revealing mounting and other structural problems.

\subsection{Side Grooves}

Table 5 shows that side grooves reduce the mean energy (by an amount much greater than that explained by the reduction in cross-sectional area), but the coefficient of variation either stayed about the same or increased slightly. Also, the specimen halves were still 
Table 3. Verification of Izod and Charpy impact machines in testing plastics

\begin{tabular}{|c|c|c|c|c|c|c|c|c|}
\hline $\begin{array}{l}\text { Specimen } \\
\text { ID }\end{array}$ & Material & $\begin{array}{c}\text { Mean } \\
\text { absorbed } \\
\text { energy }(\mathrm{J})\end{array}$ & $\begin{array}{c}\text { Standard } \\
\text { deviation } \\
(\mathrm{J})\end{array}$ & $\begin{array}{l}\text { Coefficient } \\
\text { of } \\
\text { variation }\end{array}$ & $\begin{array}{c}\text { Notch } \\
\text { radius } \\
(\mathrm{mm})\end{array}$ & $\begin{array}{c}\text { Specimen } \\
\text { dimension } \\
(\mathrm{mm})\end{array}$ & $\begin{array}{c}\text { Potential } \\
\text { energy } \\
(\mathrm{J})\end{array}$ & Comments \\
\hline \multicolumn{9}{|c|}{ Izod } \\
\hline $1-2,8-10$ & 4340 & 1.314 & 0.111 & 0.084 & 0.25 & 4 by 4 & & Remaining ligament \\
\hline $3-7$ & 6061-T6 & 2.698 & 0.176 & 0.065 & 0.50 & 4 by 5 & & Remaining ligament \\
\hline$A \& B$ & 7075-T6 & 1.573 & 0.259 & 0.165 & 0.50 & 4 by 5 & & Remaining ligament \\
\hline $11-14$ & 4340 & 2.106 & 0.558 & 0.264 & 0.50 & 4 by 5 & & Remaining ligament \\
\hline $15-19$ & 4340 & 2.511 & 0.108 & 0.042 & 0.50 & 5 by 5 & & Remaining ligament \\
\hline
\end{tabular}

\begin{tabular}{|c|c|c|c|c|c|c|c|c|}
\hline \multicolumn{9}{|c|}{ Charpy } \\
\hline $20-22$ & 6061-T6 & 3.521 & 0.162 & 0.046 & 0.50 & 4 by 5 & 5.0 & $\begin{array}{l}\text { Remaining ligament }(20 \& 21) \\
\text { Complete break-22 }\end{array}$ \\
\hline $23-25$ & 6061-T6 & 3.474 & 0.150 & 0.043 & 0.50 & 4 by 5 & 22.0 & $\begin{array}{l}\text { Remaining ligament (23\&24) } \\
\text { Complete break-25 }\end{array}$ \\
\hline $26-28$ & 6061-T6 & 3.110 & 0.300 & 0.097 & 0.25 & 4 by 5 & 22.0 & Complete breaks \\
\hline $29-31$ & $7075-\mathrm{T} 6$ & 1.172 & 0.058 & 0.050 & 0.25 & 4 by 5 & 22.0 & Complete laminate breaks \\
\hline $32-34$ & 2219-T87 & 1.316 & 0.069 & 0.052 & 0.25 & 4 by 5 & 22.0 & Complete brittle fracture \\
\hline $35-37$ & 2014-T6 & 2.894 & 0.105 & 0.036 & 0.25 & 4 by 5 & 22.0 & Complete laminated fracture \\
\hline $38-40$ & 2024-Т351 & 1.868 & 0.088 & 0.047 & 0.25 & 4 by 5 & 22.0 & Complete brittle fracture \\
\hline $41-43$ & 6061-T6 & 3.084 & 0.000 & 0.000 & 0.50 & 4 by 5 & 358 & Compare to $26,27,28,(44)$ \\
\hline 44 & 6061-T6 & 3.168 & 0.000 & 0.000 & 0.25 & 4 by 5 & 358 & \\
\hline $\mathrm{C}-\mathrm{F}$ & 7075 & 1.644 & 0.142 & 0.086 & 0.25 & 4 by 5 & 358 & \\
\hline $45-48$ & 4340 & 3.022 & 0.105 & 0.035 & 0.25 & $5 \times 5$ & 358 & \\
\hline $56-72$ to & & & & & & & & \\
\hline $\begin{array}{l}56-74 \\
56-1 \text { to }\end{array}$ & 4340-LL56 & 4.441 & 0.100 & 0.023 & 0.25 & 4 by 5 & 22 & \\
\hline $\begin{array}{l}56-10 \\
56-31 S \text { to }\end{array}$ & 4340-LL56 & 4.459 & 0.089 & 0.020 & 0.25 & 4 by 5 & 22 & No side groove \\
\hline $\begin{array}{l}56-40 S \\
\text { LL11-1 to }\end{array}$ & 4340-LL56 & 2.476 & 0.068 & 0.028 & 0.25 & 4 by 5 & 22 & Side groove \\
\hline $\begin{array}{l}\text { LL11-10 } \\
\text { LA46-1 to }\end{array}$ & 4340 & 2.739 & 0.068 & 0.025 & 0.25 & 4 by 5 & 22 & Machine \#2, no side groove \\
\hline LA46-10 & 4340 & 1.519 & 0.339 & 0.223 & 0.25 & 4 by 5 & 22 & Machine \#2, side groove \\
\hline G7-G8 & 2219-T87 & 0.732 & 0.041 & 0.056 & 0.25 & 4 by 5 & 22 & Machine \#2, no side groove \\
\hline G9-G10 & $202 \mathrm{~T} 4-351$ & 1.071 & 0.000 & 0.000 & 0.25 & 4 by 5 & 22 & Machine \#2, no side groove \\
\hline G13-G14 & 2014-T6 & 1.844 & 0.732 & 0.397 & 0.25 & 4 by 5 & 22 & Machine $\# 2$, no side groove \\
\hline G3-G4 & 7075-T6 & 1.044 & 0.149 & 0.143 & 0.50 & 4 by 5 & 22 & Machine \#2, no side groove \\
\hline G1-G2 & 6061-T6 & 2.027 & 0.081 & 0.040 & 0.50 & 4 by 5 & 22 & Machine $\# 2$, no side groove \\
\hline G5-G6 & 6061-T6 & 2.278 & 0.691 & 0.304 & 0.25 & 4 by 5 & 22 & Machine \#2, no side groove \\
\hline G11-G12 & 7075-T6 & 0.637 & 0.041 & 0.064 & 0.25 & 4 by 5 & 22 & Machine $\# 2$, no side groove \\
\hline
\end{tabular}

joined by a similarly sized ligament. These unexpected results do not support more than a few confirming tests on aluminum alloys in any future evaluation.

\subsection{Notch Radius}

Table 6 shows the effect of halving the notch radius from $0.5 \mathrm{~mm}$ to $0.25 \mathrm{~mm}$. In general, notches are stress concentrators that reduce the ability of a material to sustain a load and promote brittle, rather than ductile, failure [8]. In addition, sharper notches should decrease the scatter, as a sharper notch increases the local stress at the crack, and its variable contribution to the scatter.
However, these data show that the consistency was much worse with the sharper notch, although the absorbed energy indeed decreased by about $10 \%$. Once again, these disappointing results seem to minimize the value of including a large number of tests for this variable in any future evaluations.

\subsection{Machine Capacity and Design}

Table 7 shows the effect of machine capacity and design. There was as much as $45 \%$ variation in the energy as the machine capacity was changed from $22 \mathrm{~J}$ to $358 \mathrm{~J}$, at least for alloy 7075 . This variation is several 
Table 4. Effect of alloy

\begin{tabular}{lcccc}
\hline Material & $\begin{array}{c}\text { Number } \\
\text { of } \\
\text { specimens }\end{array}$ & $\begin{array}{c}\text { Mean } \\
\text { absorbed } \\
\text { energy }(\mathrm{J})\end{array}$ & $\begin{array}{c}\text { Standard } \\
\text { deviation } \\
(\mathrm{J})\end{array}$ & $\begin{array}{c}\text { Coefficient } \\
\text { of } \\
\text { variation }\end{array}$ \\
\hline 4340 & 3 & 4.441 & 0.100 & 0.023 \\
$2014-\mathrm{T6}$ & 3 & 2.894 & 0.105 & 0.036 \\
2024-T351 & 3 & 1.868 & 0.088 & 0.047 \\
2219-T87 & 3 & 1.316 & 0.069 & 0.052 \\
6061-T6 & 3 & 3.110 & 0.300 & 0.097 \\
7075-T6 & 3 & 1.172 & 0.058 & 0.050 \\
\hline
\end{tabular}

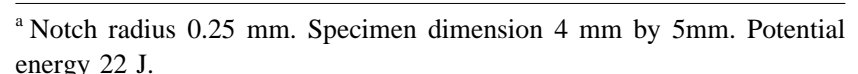

Table 5. Effect of side grooves ${ }^{\mathrm{a}}$

\begin{tabular}{lccccc}
\hline \hline Material & $\begin{array}{c}\text { Number } \\
\text { of } \\
\text { specimens }\end{array}$ & $\begin{array}{c}\text { Mean } \\
\text { absorbed } \\
\text { energy }(\mathrm{J})\end{array}$ & $\begin{array}{c}\text { Standard } \\
\text { deviation } \\
(\mathrm{J})\end{array}$ & $\begin{array}{c}\text { Coefficient } \\
\text { of } \\
\text { variation }\end{array}$ & $\begin{array}{c}\text { Side } \\
\text { grooves }\end{array}$ \\
\hline 4340 & 10 & 4.459 & 0.089 & 0.020 & $\mathrm{~N}$ \\
4340 & 10 & 2.476 & 0.068 & 0.028 & $\mathrm{Y}$ \\
\hline
\end{tabular}

${ }^{a}$ Notch radius $0.25 \mathrm{~mm}$. Specimen dimension $4 \mathrm{~mm}$ by $5 \mathrm{~mm}$. Potential energy $22 \mathrm{~J}$.

Table 6. Effect of notch radius ${ }^{\mathrm{a}}$

\begin{tabular}{lccccc}
\hline \hline Material & $\begin{array}{c}\text { Number } \\
\text { of } \\
\text { specimens }\end{array}$ & $\begin{array}{c}\text { Mean } \\
\text { absorbed } \\
\text { energy }(\mathrm{J})\end{array}$ & $\begin{array}{c}\text { Standard } \\
\text { deviation } \\
(\mathrm{J})\end{array}$ & $\begin{array}{c}\text { Coefficient } \\
\text { of } \\
\text { variation }\end{array}$ & $\begin{array}{c}\text { Side } \\
\text { grooves }\end{array}$ \\
\hline $6061-\mathrm{T} 6$ & 3 & 3.474 & 0.150 & 0.043 & 0.50 \\
$6061-\mathrm{T} 6$ & 3 & 3.110 & 0.300 & 0.096 & 0.25 \\
\hline
\end{tabular}

${ }^{\mathrm{a}}$ Specimen dimension $4 \mathrm{~mm}$ by $5 \mathrm{~mm}$. Potential energy $22 \mathrm{~J}$.

Table 7. Effect of machine capacity ${ }^{\mathrm{a}}$

\begin{tabular}{lcccccc}
\hline \hline Material & $\begin{array}{c}\text { Number } \\
\text { of } \\
\text { specimens }\end{array}$ & $\begin{array}{c}\text { Mean } \\
\text { absorbed } \\
\text { energy }(\mathrm{J})\end{array}$ & $\begin{array}{c}\text { Standard } \\
\text { deviation } \\
(\mathrm{J})\end{array}$ & $\begin{array}{c}\text { Coefficient } \\
\text { of } \\
\text { variation }\end{array}$ & $\begin{array}{c}\text { Notch } \\
\text { radius } \\
(\mathrm{mm})\end{array}$ & $\begin{array}{c}\text { Machine } \\
\text { potential } \\
\text { energy }(\mathrm{J})\end{array}$ \\
\hline 6061-T6 & 3 & 3.521 & 0.162 & 0.046 & 0.50 & 5 \\
$6061-\mathrm{T} 6$ & 3 & 3.474 & 0.150 & 0.043 & 0.50 & 22 \\
$6061-\mathrm{T} 6$ & 3 & 3.110 & 0.300 & 0.097 & 0.25 & 22 \\
$6061-\mathrm{T} 6$ & 3 & 3.084 & 0.000 & 0.000 & 0.50 & 358 \\
6061-T6 & 1 & 3.168 & 0.000 & 0.000 & 0.25 & 358 \\
7075-T6 & 4 & 1.644 & 0.142 & 0.086 & 0.25 & 358 \\
7075-T6 & 3 & 1.172 & 0.058 & 0.050 & 0.25 & 22 \\
\hline
\end{tabular}

${ }^{\text {a }}$ Specimen dimension $4 \mathrm{~mm}$ by $5 \mathrm{~mm}$. Potential energy $22 \mathrm{~J}$.

times greater than the standard deviation and so appears to be significant. However, the effect does not seem significant for alloy 6061-T6, with the effect being less than the standard deviation. This lack of significance is also evident for changes in the machine range from $5 \mathrm{~J}$ to $22 \mathrm{~J}$, comparison of plastics impact machines from two different manufacturers, and comparison between the plastics impact machines (with capacities of $22 \mathrm{~J}$ ) and a metals impact machine (with a capacity of $358 \mathrm{~J}$ ). In retrospect, it would have been better to have made more specimens of 4340 and repeated this test using specimens having a smaller standard deviation. However, both these results support the robustness of the pendulum impact machine concept and indicate that it has been implemented consistently in these different machine designs. 


\subsection{Charpy Versus Izod}

The limited data prevent us from drawing strong conclusions about the effect of test orientation (Izod versus Charpy), but an informal comparison of the two types of data summarized in Table 3 reveals no clear distinction between the two. It seems as though the difference in mean energy between Izod and Charpy tests is less than the variability due to other test parameters and so cannot be resolved. The same statement can be made for the CVs.

\section{Conclusions}

1. At low energies (low end of the machine capacity), certain metallic alloys have CVs that are about half that of the plastics in this range. This seems to support the option of using metal impact specimens to verify the performance of plastics impact machines at the low end of their range.

2. Metal specimens would increase the load on the machine striker and frame, permitting better resolution of machine rigidity and mounting problems.

3. Verification testing provides valuable performance data. For example, the data for alloy 6061-T6 indicate that two different designs of impact machines for plastics produce results that agree within the uncertainty that can be attributed to the specimens alone.

\section{Acknowledgment}

We appreciate the assistance of Jennifer Caragol in revising and formatting the tables.

\section{References}

[1] ASTM Standard E 23, Standard Test Methods for Notched Bar Impact Testing of Metallic Materials, Vol 03.01, American Society for Testing and Materials, Conshohocken, Pennsylvania (1999).

[2] Research Report RR: D20-1134, untitled, available from American Society for Testing and Materials, Conshohocken, Pennsylvania.

[3] Research Report RR: D20-1021, untitled, available from American Society for Testing and Materials, Conshohocken, Pennsylvania.

[4] Smithell's Metals Reference Book, Sixth Ed., E. A. Brandes, Butterworths, London (1983) pp. 15-3.

[5] Guide to Selecting Engineered Materials, Advanced Materials and Processing, Vol. 137 (6), ASM International, Materials Park, Ohio, June 1990, p. 23.

[6] Metals Handbook Ninth Edition, (Vol. 2) - Properties and Selection: Nonferrous Alloys and Pure Metals, ASM International, Materials Park, Ohio (1979) p. 31.
[7] ISO Standard DIS 13802, Plastics - Pendulum impact-testing machines-Validation of Charpy, Izod, and tensile impact-testing machines, available from the ISO secretariat AFNOR (1995).

[8] Metals Handbook Ninth Edition, (Vol. 11)-Failure Analysis and Prevention, ASM International, Materials Park, Ohio (1986) p. 85.

About the authors: Tom Siewert is a metallurgist in the Materials Reliability Division of the NIST Materials Science and Engineering Laboratory. Dan Vigliotti is a technician in the Materials Reliability Division of the NIST Materials Science and Engineering Laboratory. Lisa Dirling was a student at the University of Colorado in Boulder. Chris McCowan is a metallurgist in the Materials Reliability Division of the NIST Materials Science and Engineering Laboratory. The National Institute of Standards and Technology is an agency of the Technology Administration, U.S. Department of Commerce. 